\title{
The interaction of employee trust \& ethical decision making
}

\author{
Evangelia Fragouli
}

University of Dundee, UK

\section{Keywords}

Trust, ethical decision making, leadership

\begin{abstract}
Trust is seen to include both emotional and cognitive dimensions and to function as a deep assumption underwriting social order. In the past three decades, the importance of trust in the workplace $\mathcal{E}$ its influence on organizational performance has been recognized by research scholars, and practitioners. This research paper aims to examine the impact of employee trust on leaders' ethical decision-making. This study applies literature review method to address the above subject showing that the impact of employee trust on leaders' ethical decision-making relates to organizational aspects, as well as personal characteristics of leaders. Consideration of organizational aspects include performance, effective communication, and organizational culture. The personal aspects relate to leadership self-certification, guilt, rational attitude, leader learning, and moral model. Further, this study suggests that employee trust enhances e\& \& motivates leaders to make ethical decisions. However, organizational culture and leadership personal characteristics may have a negative impact on ethical decision-making. This study suggests that organizations could make collective decisions on major issues to reduce the impact of these negative factors on ethical decision-making.
\end{abstract}

\section{Introduction}

Negative working atmosphere creates a highly stressful and undesirable environment for everyone. Within such organizations, employees withhold their talents, creativity, energy, and passion. As a result, they lose productivity, their innovation capabilities, their competitive edge, and more. Trust in the workplace has a big impact on how employees collaborate and work together. When employees trust their employers, they are much more likely to work together towards achieving the same ultimate business goals. According to Mayer (1995 as cited in Kumar et.al, 2017), the idea of trust focuses on the perception of trustworthiness of trustee (who is the person that is being trusted) as an antecedent to interpersonal trust; trust is defined as the willingness of an individual to make him or herself vulnerable to the actions or conduct of another. According to Robinson (1996 as cited in Kumar et.al, 2017), "trust refers to one's expectation, assumption, or belief about the probability that another's future action will be beneficial, favourable or at least not detrimental to one's interests" (p.6). In 1998 Rousseau (as cited in Kumar et.al, 2017) emphasized two crucial features which appear to be the core to the most definitions of trust: "positive expectations and willingness to accept vulnerability." The positive expectations include confident beliefs kept in the trustors that the trustee is competent, honest, and caring enough that is worthy of their trust. Next, the willingness is to accept almost all the vulnerability reflects an intention to depend on others. In consequence, employee trust can be summarised as the employees keeping expectations on the corporate leaders currently and in the future and the employees are also willing to take risk for the corporate leaders to do something that is not in the employees' plan, additionally, the employees also empowered the corporate leaders the power to hurt them. According to Barney (1991 Kumar et.al, 2017), employees in an organization must be talented enough to achieve sustainable competitive advantage and the competitive advantages are derived from the efforts and capabilities of employees. Trust is significantly related to group commitment, affective commitment, and job satisfaction (Kumar \& Saha, 2017). Affective commitment is the attitude that reflects the thoughts such as identification, attachment and loyalty to the subject, affective commitment has a strong relationship with group level outcomes and citizenship conducts. Group commitment helps the organization to prompt the commitment of employees toward a work group and helps to identify employees themselves with their work group (Levine \& Moreland, 2002 as cited in Kumar et.al, 2017). Therefore, it is important and necessary to build trust among employees and employers.

Companies' decision-making normally has a serious impact on their stakeholders. Coupled with the exposure of numerous corporate scandals, the public is increasingly paying attention to companies' day-to-day operations. As a result, experts have conducted a lot of research on the ethics 
of decision-making. Many of these studies are about factors that influence ethical decision-making. Specifically, they focus on the influence of a leader's individual characteristics (such as gender, education, and experience) and organizational characteristics (such as atmosphere, culture, and system) on ethical decision-making ( $\mathrm{O}^{\prime}$ Fallon and Butterfield, 2005). However, these studys; seldom involve the impact of employee trust on leadership ethical decisions. It is widely acknowledged that employee trust is an important measure of leadership, so leaders are always trying to win their employees' trust (Dirks and Ferrin, 2001). It, therefore, makes sense to examine the connection between the employee trust and ethical decision making. This research will fill the existing gap by synthesizing relevant previous research.

This research begins with the definition of trust, ethical decision making, and employee trust; and then analyses the factors that influence employee decision-making by referring to previous literature. By comparing and analysing these factors, this study tries to find its positive as well as negative impacts. Finally, the study provides suggestions on how to lead trusted leaders in making the ethical decisions. The literature review method will be used in this research. This method is considered as the most commonly used research method by students and researchers (Turner, 2018). Imel (2011) treats a literature reviews as part of larger study or as part of research efforts. This study will use this method to analyse literatures related to employee trust and leadership ethical decisions.

\section{The context of trust and employee trust}

Trust is difficult to be defined (Simpson, 2012). However, most scholars claim that trust is a state of relationship based on psychological expectations. For example, the definition from Gambetta (1988, p116) is, "A particular level of the subjective probability with which an agent assesses that another agent or a group of agents will perform a particular action, both before he can monitor such action (or independently of his capacity ever to be able to monitor it) and in a context in which it affects his own action." Furthermore, Khodyako (2007) indicates four bases of a trust relationship: (1) the reputation of partners and actors, (2) an assessment of the current behavioural environment, (3) assumptions about partner behaviour, and (4) the belief in the honesty and morality of the other side'.

Employee trust 'develops when individuals must generalise their personal trust to large organizations made up of individuals with whom they have low familiarity, low interdependence and low continuity of interaction' (Lewicki and Bunker, 1995, p.270). Therefore, the foundation of employee trust is the trust between people. Siebert, Martin, and Bozic (2016) argue that employee trust spans all levels of the organization, including trust between employees, employee trust in senior management, employee trust in their supervisor / leader, and employee trust in the entire organization. A leader's ability to build trust among employees plays a major role in determining their success as a leader in an organization (Fragouli, 2019). In addition, Mayer, Davis \& Schoorman (1995) argue that in the process of building trust, the leader's trustworthiness will be examined by employees on three components: competence, kindness, and honesty. Competence means a leader has the ability to do right thing. Kindness indicates whether the leader's personality is compassionate, caring for employees, kind, empathetic, and committed to common goals. Honesty indicates objectivity and fairness to the trustee. The role of honesty in moral decision-making is considered to be the most important one (Lee \& Selart, 2014). In addition, while developing employee trust, an important basis is the performance of previous leaders in the organization (Borum, 2010). In cases where leaders and organizations made fair and ethical decisions in the past, employees are more likely to trust them. On the contrary, if leaders and organizations harmed the employees by behaving unethically, the employees may treat them as untrustworthy.

\section{Conceptualizing the context of ethical decision-making}

An ethical decision is a decision that is largely accepted by society, both legally and ethically. On the other hand, unethical decisions are either illegal or morally unacceptable by larger communities (Pohling et.al, 2016). Rest (1986) divides the ethical decision-making process into four phases, ;(1) acknowledging moral or ethical issues; (2) making judgments based on certain ethical standards, (3) placing the importance of the ethical part of the decision on all other concerns, and (4) acting on ethical principles.

A large number of previous studies have shown that the factors that influence leaders to make ethical decisions can be divided into three aspects (Kuntz et al., 2012). The first is the leader's personal factors, such as gender, education, and work experience. The second is the organizational factors, such as organizational culture, organizational atmosphere, and organizational system. The third is 
external environmental factors, such as business norms or a country's legal system. However, this study discusses the impact of employee trust that does not change the external environment of the organization. This study will, therefore, conduct the analysis from the personal and organizational perspectives.

\section{Organizational Perspective}

Organizational Performance: Many previous studies on trust have been based on the social exchange theory (Blau, 1964). According to this theory, the trust relationship between the two parties is an exchange relationship, and mutual trust may have an important impact on the two parties' behaviour and intention. When employees trust their leaders, they may be more willing to improve job performance to provide benefits (Brown et al., 2015; Hsieh \& Wang 2015; Brower et al., 2008). Additionally, they are likely to have a more positive attitude and willingness to maintain exchange relationships (Dirks \& Ferrin, 2002; Mayer \& Gavin, 2005). From another perspective, trusted leaders also benefit from this trust relationship such as through better organizational performance and lower turnover rates). As such, trusted leaders should also be active in maintaining this relationship. However, social exchange theory also argues that subordinates do not trust their leaders unconditionally, but that they may have a history of successful exchange (Blau, 1964). In other words, leaders have proven themselves to be trustworthy, or competent, kind, and honest. As a result, trusted leaders continue to make ethical decisions to strengthen employee trust and thereby improve organizational performance. In addition, imitation theory proves from another perspective that trusted leaders may make ethical decisions. According to the theory, when employees trust their leaders, they may have the motivation to imitate their leaders' behaviour (Mayer et al, 2009). That means an ethical leader will ultimately affect the employees' ethics and as a result increase the organizational performance. Similarly, unethical leaders can also negatively influence employees resulting in unethical behaviour among them and decreasing organizational performance in general. For these two reasons, employee trust increases the likelihood that leaders will make ethical decisions.

Effective Communication: During the process of employees building trust in their leaders, they are often willing to communicate with them, share their knowledge, and get more information that will help the leaders make ethical decisions. Different employees have different educational backgrounds, work experiences and skills. When employees trust their own leaders, they are more willing to share their opinions and suggestions. Thus, leaders can get effective information provided by employees from different perspectives and positions (David, 2005). This information can help leaders think more comprehensively about an issue before making a decision. As a result, the decision they come to is likely to be effective as well as ethical. It is easier for employees and leaders to communicate effectively when employees trust in leaders (Mishra and Morrissey, 1990). Through communication, leaders can better understand the real thinking of employees and the direct benefits that employees want. When leaders understand their employees better, they will consider their interests more when making decisions. Taking their employees' interests into consideration may help leaders to make more ethical decisions. When employees trust leaders, communication will be more effective between them. Through effective communication, the leader can anticipate the employees' emotional changes and reactions and provide the necessary assistance in good time. Leaders can, therefore, understand their employees' emotions and thoughts when making decisions, and through this understanding they can make the decisions in an ethical manner (Kelloway, 2012).

Organizational Culture: Son Hing et al., (2007) believe that when higher social dominance (SOD) leaders are combined with right-wing authoritarianism (RWA) followers, leaders are more likely to make unethical decisions, and followers also trust leaders' decisions. In an organization, ethical decision making is made in a hierarchically marked social environment. In this social environment, when the superior expresses the idea of making unethical decisions about the subordinates, the hierarchical relationship between them may influence subordinates to accept it. Moreover, the authors mention that RWA people will obey people they believe to be legitimate authorities and have a tendency to engage in authoritarian aggression. The high SOD leaders' authority is an important reason for employee trust. Compared with the leaders from low SOD, they are harder on their employees and lack the patience to communicate with the public. Thus, when RWA followers trust leaders with higher SOD, they are prone to dictatorship. When the leader becomes the embodiment of 
authority, leveraging their authority and their followers' trust, it's easier to deceive them and convince them that the leader is making the right decisions. The sense of guilt that results from unethical decisions is greatly reduced. The blind trust of followers reduces the cost of leaders' unethical behaviour.

\section{Personal Perspective}

Henry Stimson necessitated trust in an individual as a fundamental aspect in ensuring that someone has the virtue of being trustworthy (Seldon, 2011). Employee trust has been described to focus ideally on the trust employers are accorded by their employees, thus the power of employee and the organization they work for is unequal. It is never an assurance that an organization's employees will trust in their leaders, rather it must be earned from the start and subsequently maintained over the course of the employees stay at the organization. In this part, information on employee trust effect on leadership decisions was mostly available for self-certification, guilt, rational attitude, leaders' learning, moral model, and pressure in decision making.

Self-certification: Prior studies have shown that employee trust affects their leader's decision making through self-certification. This is where the leader experiences pressure to prove his or her competence through the decisions they make. A leader builds trust by being approachable and friendly to his employees, as well as fulfilling their promises. According to Kouzes and Posner (2010), trust creates a willingness in the employees to follow their leader. As such, when a leader is aware of the fact that employees under them have trust in them, they come under pressure to ensure that they do not lose this trust as they will have lost the influence they have on the employees. Therefore, based on this fact the leader is pushed towards making more ethical decisions as they try to keep the trust they have on their employees. Additionally, employee trust contributes to ethical decision making by improving access to information between the leader and the employees, this is according to a study by Fragouli (2019). The finding of this study further ascertained this notion of self-certification, as it showed that when employees trusted their leaders, the leaders leaned towards proving their ethics in the decision they made.

The feeling of 'being guilty': Leaders who have gained their employees' trust may feel guilty if they make unethical decisions, such as those that are unfair to employees or those that risk their safety at work. Guilt is a cognitive experience that occurs when a person believes that he or she has compromised their own standards of conduct or violated universal ethical standards and is primarily responsible for the act (Baumeister, Stillwel \& Heatherton, 1994). Lee \& Selart (2014) argue that feelings of guilt are likely to prompt, leaders to make more ethical decisions. In addition, the relationship between the employee and the leader determines whether the leader will feel guilty after making an unethical decision. However, Lee and Selart's research also shows that not all people make morally acceptable decisions because of guilt. Some leaders may deliberately ignore the guilty feelings stemming from their unethical decisions. Further, leaders might collude with trusted employees to make unethical decisions to a third party inside or outside of the organization. Similarly, another study by Nicker and Sullivan (2018) suggests that trust relationships may increase the tolerance of moral issues, especially when these issues can deepen trust relationships. For example, the emissions scandal of Volkswagen in 2015 could be seen as an unethical decision by leaders and employee representatives. Although they did not directly participate in the scandal, the ambitious goals set by the board and the limited budget did lead to the root cause of the problem (Crête, 2016).

Rational Attitude: The ethical decision-making model established by Woiceshyn (2011) divides the handling of business ethics decisions into conscious processing and subconscious processing and believes that leaders with rational self-interested ideas are more likely to make ethical decisions. Unethical decisions may harm the interests of decision makers themselves, although they may bring temporary benefits. When maintaining a rational attitude, decision makers can maintain a long-term perspective, not deceived by temporary interests. Moreover, during the process of leader's subconscious judgment in the face of decision-making, maintaining rationality is one of the important factors making the right choice.

Leaders' Learning: Employee trust may help leaders learn from mistakes and avoid making mistakes and unethical decisions in the future. Once leaders make mistakes or make unethical decisions during 
the decision-making process, they will not only be psychologically self-stressed, but also more likely to lose support from employees and the company（Schyns and Hansbrough, 2010）. However, when employees choose to continue trusting the leaders, it gives the leaders a strong encouragement in spirit, and also greatly encourages the leaders to learn from the previous mistakes, thus avoid making the same mistakes in the future. This is a process in which both employees and leaders give each other trust and understanding (Carmeli et.al, 2012).

Moral Model: Trusted leaders have been demonstrated to have the tendency of becoming moral agents in the organization (Fragouli, 2019). According to Fragouli's study, it was found that trusted leaders harboured a feeling of responsibility to be good to their employees which further skewed their decision to be more ethical. Moreover, trusted leaders tend to bear a sense of accountability and accepting responsibility for the eventual outcome (Memiyanty, Putera, and Salleh, 2010). According to Memiyanty, Putera, and Salleh, the leader's ethical awareness is a key in employee trust. This means that leaders, who have their employee trust, must in the first place have had ethical awareness. Thus, these leaders are pushed to keeping this ethical awareness through their knowledge that their employee trusts them, thus making ethical decisions.

Pressure: Based on the analysis above, trusted leaders have proven that they are trustworthy, and they need to be proven continuously. However, employee trust can also put pressure on leaders to some extent. McGeer and Philip (2017) argue that moral life is inherently a struggle, including a constant struggle to maintain appreciation for trust-related reasons, and to maintain a response to those reasons. As a result, leaders may feel the pressure of trust when making decisions. However, many previous studies have shown that stress can have positive or negative effects on leadership decisions, and even make wrong decisions.

\section{Discussion}

Based on the above research, it is clearly shown that leaders who have the trust of their employees are more likely to make ethical decisions because trust bestowed upon these leaders encourages them to learn from their earlier failures. In organizations, leaders are tasked with playing the critical role of keeping as well as the establishment of ethical culture within the organization sections they lead. As such, with such responsibility laid placed on these leaders, they often must lead by example as they cannot call on their employees to practice ethical decision making while they themselves do not practice the same (Fragouli, 2019). However, many of today's organizations place more emphasis on a leader's ability, academic knowledge, and techniques at the expense of the leader's morality, which has led to many employees in the organization not having any trust for their leaders. In addition to employee learning, employee trust plays a role in a leader's ethical decision making as this trust induces the need for the leader to be an effective leader. On the other hand, effective leadership is an attribute that cannot separate from ethical behaviour as they are intertwined (Siltaoja, Lämsä and Kujala, 2019). For leadership to ensure achieving any meaningful progress, moral collapse cannot go with the progress. Upright morality is the precursor of a successful organization's successful achievement of its goals. This is because for the organization to function, teamwork is a core attribute that must be present, teamwork cannot exist where moral decadence is present. As such, this leaves the leader with the conscience that they are being watched by those under them and thus they set the pace in ethical conduct. Excellence in leadership cannot be achieved without moral uprightness, a trait that reflects in the leader's moral vision, integrity, value for others and most of all the virtue of responsibility. With these traits, the leader is bound to make ethical decisions leadership.

However, according to Michael and Kenneth, the personal factors can also lead to unethical decisions, these include the leader's knowledge, personal goals, culture, and personality $\left(\mathrm{O}^{\prime}\right.$ Fallon and Butterfield, 2005). To begin with, knowledge determines the chances of one making informed decisions on a matter, which denoted ethical choices. Values, on the other hand, determine an individual's judgment and standard behaviour. For instance, some individuals have no value of integral behaviour. Thus, they would have no problem making unethical decisions that affect other employees negatively. Gender has also been shown to be contributing individual factor to one making ethical decision. As such, according to research, it has been shown that women tend to make more ethical decision as compared to men ( $\mathrm{O}^{\prime}$ Fallon and Butterfield, 2005). In addition to these, other factors such as cultural norms also affect a leader's ability to make ethical decisions, as it is a determinant of one's values and perspective on various matters. 
In order for an organization to reduce the effect of these personal factors, it is important the organization to do the following: First, the organization can institute making of collective decisions, these reduce the chances of personal bias from resulting in unethical decisions. They also help in collective knowledge, where every employee gives their insight on the matter allowing the making of an informed decision that is also ethical. In addition to this step, an organization can also enroll their leaders in training activities that enlighten them on the positive impact of ethical decisions in an organization. Leaders, who understand the impact of ethical decisions on sustaining employee trust in them as their leader, tend to ensure that they make well informed and ethical decisions. Ethical leaders show unwavering commitment to their moral believes and values during decision making and problem-solving, ensuring they give the employees a chance to trust that the decisions they make are for the best of the organization and the employees in general, further enhancing their trust in their leadership.

\section{Conclusion \& Limitations}

This study explores the relationship between employee trust and ethical decision making. First it introduces relevant definitions, including trust, ethical decision making, and employee trust. This paper then studies the influences of employee trust on leadership ethics through literature review. The influences are divided into organizational and personal perspectives.

The findings indicate that trusted leaders may make more ethical decisions for the benefit of the organization. This is because ethical decisions can improve organizational performance and increase organizational communication efficiency. However, due to the influence of leadership authority, leaders can also make unethical decisions. Considering the impact from a personal perspective, leaders may be affected by the feeling of self-certification, guilt, rational attitude, leaders' learning, moral model, and the pressure of trust during ethical decision-making. Overall, this paper argues that leaders who are trusted by employees are more likely to make ethical decisions. However, leaders' and employees' personalities also play a role in decision-making. This paper further recommends that using decision-making groups to make major decisions can reduce the impact of personal reasons on decision-making.

The findings of this paper have important application value. To improve the ethical standards of decision-making, it is important for organizations to develop employee trust. However, to reduce the moral hazard of individual factors for decision making, the group decision-making method can be used by organizations during major decisions. Furthermore, an organization can also involve their leaders in training activities that allow them to understand the positive impact of ethical decision making in the organization.

The main limitations of the present study regard the methodology and the perspective of the research. The findings based on the literature review approach could be enhanced by the administration of an empirical study showing also the impact of employee trust on the interaction of the organizational \& personal aspects of leaders \& leadership, as well as, on building leaders' trust towards others. The latter would also enrich the perspective of the study.

\section{Recommendations}

This research studies the relationship between employee trust and the ethics of leadership decision-making and draws a conclusion through literature collection and literature analysis. However, due to time constraints, this study was not able to collect and analyse all relevant literatures. In addition, this study only collated previous studies to discover the relationship between employee trust and ethical decision making but did not collect data for verification. As a result, the conclusions of this study may have limitation. However, since both employee trust and ethical decision making are important items in management, their connections deserve further research. Subsequent research is suggested to collect literature more extensively or verify the conclusions of this study by data collection and analysis.

\section{References}

Baumeister, R.F., Stillwell, A.M. \& Heatherton, T.F. (1994). Guilt: An interpersonal approach, Psychological Bulletin, 115 (2), pp. 243-267

Borum, R. (2010). The Science of Interpersonal Trust. [online] Scholar Commons. Available at: http://scholarcommons.usf.edu/mhlp_facpub/574 [Accessed 17 Nov. 2019].

Brower, H., Lester, S., Korsgaard, M. and Dineen, B. (2008). A Closer Look at Trust Between Managers and Subordinates: Understanding the Effects of Both Trusting and Being Trusted on Subordinate Outcomes. Journal of Management, 35(2), pp.327-347. DOI: 10.1177/0149206307312511 
Brown, S., Gray, D., McHardy, J. and Taylor, K. (2015). Employee trust and workplace performance. Journal of Economic Behavior \& Organization, 116, pp.361-378. DOI: 10.1016/j.jebo.2015.05.001

Carmeli, A., Tishler, A. \& Edmondson, A.C., (2012). CEO Relational Leadership and Strategic Decision Quality in Top Management Teams: The role of team trust and learning from failure. Strategic Organization, 10 (1), 31-54.

Crête, R. (2016). The Volkswagen Scandal from the Viewpoint of Corporate Governance. European Journal of Risk Regulation, 7(1), pp.25-31. DOI: 10.1017/s1867299x0000533x

David, F. (2005). Strategic management: Concepts and cases. (10th ed.). New Jersey: Pearson Prentice Hall.

Dirks, K. T., \& Ferrin, D. L. (2001). The role of trust in organizational settings. Organization Science, 12: 450-467.

Dirks, K. T., \& Ferrin, D. L. (2002). Trust in leadership: Meta-analytic finding and implications for research and practice. Journal of Applied Psychology, 87: pp.611-628.

Fragouli, E. (2019). Employee trust and ethical leadership decision making. [online] Discovery - the University of Dundee Research Portal. Available at: https://discovery.dundee.ac.uk/en/publications/employee-trustand-ethical-leadership-decision-making [Accessed 17 Nov. 2019].

Gambetta, D. (1988) 'Can We Trust Trust?', in D. Gambetta (ed.) Trust. Making and Breaking Cooperative Relations, pp. 213-37

Hsieh, C. and Wang, D. (2015). Does supervisor-perceived authentic leadership influence employee work engagement through employee-perceived authentic leadership and employee trust? The International Journal of Human Resource Management, 26(18), pp.2329-2348. DOI: 10.1080/09585192.2015.1025234

Imel, S. (2011). Writing a literature review. In Rocco, T. S., \& Hatcher, T., The handbook of scholarly writing and publishing, pp. 145-160. San Francisco, CA: Jossey-Bass

Kelloway, E.K., Turner, N., Barling, J. and Loughlin, C., 2012. Transformational leadership and employee psychological well-being: The mediating role of employee trust in leadership. Work \& Stress, 26(1), pp.3955.

Kouzes, J.M., and Posner, B.Z., 2010. The truth about leadership: The no-fads, heart-of-the-matter facts you need to know. John Wiley \& Sons.

Kuntz, J., Kuntz, J., Elenkov, D. and Nabirukhina, A. (2012). Characterizing Ethical Cases: A Cross-Cultural Investigation of Individual Differences, Organisational Climate, and Leadership on Ethical DecisionMaking. Journal of Business Ethics, 113(2), pp.317-331.

Kumar, S.P. \& Saha, S., (2017). Influence of Trust and Participation in Decision Making on Employee Attitudes in Indian Public Sector Undertakings. SAGE Open, 7(3), pp.1-13.

Lee, W. and Selart, M. (2014). The influence of emotions on trust in ethical decision making. Problems and Perspectives in Management, 12(4), pp.573-580.

Lewicki, R.J. and Bunker, B.B. (1995). 'Trust in relationships: a model of trust development and decline', in B.B. Bunker and J.Z. Rubin (eds), Conflict, Cooperation, and Justice, San Francisco, CA: Jossey Bass.

Mayer, R. C., \& Gavin, M. B. 2005. Trust in management and performance: Who minds the shop while the employees watch the boss? Academy of Management Journal, 48: 874-888.

Mayer, R., Davis, J. and Schoorman, F. (1995). An Integrative Model of Organizational Trust. The Academy of Management Review, 20(3), p.709. DOI: 10.5465/AMR.1995.9508080335

Mayer, D., Kuenzi, M., Greenbaum, R., Bardes, M. and Salvador, R. (2009). How low does ethical leadership flow? Test of a trickle-down model. Organizational Behavior and Human Decision Processes, 108(1), pp.1-13. DOI: $10.1016 /$ j.obhdp.2008.04.002

McGeer, V., and Philip P. (2017). "The Empowering Theory of Trust." In the Philosophy of Trust, edited by Faulkner and Simpson, 14-34. Oxford: Oxford University Press.

Memiyanty, A., Putera, M. and Salleh, K. (2010). Notice of Retraction: Ethical leadership and employee trust: Governance perspective. IEEE International Conference on Information and Financial Engineering. 2010 2nd

Mishra, J. and Morrissey, M.A., (1990). Trust in employee/employer relationships: A survey of West Michigan managers. Public personnel management, 19(4), pp.443-486.

Niker, F. and Specker Sullivan, L. (2018). Trusting Relationships and the Ethics of Interpersonal Action. International Journal of Philosophical Studies, 26(2), pp.173-186. DOI: 10.1080/09672559.2018.1450081

O'Fallon, M. and Butterfield, K. (2005). A Review of The Empirical Ethical Decision-Making Literature: 19962003. Journal of Business Ethics, 59(4), pp.375-413. DOI : 10.1007/s10551-005-2929-7

Pohling, R., Bzdok, D., Eigenstetter, M., Stumpf, S. and Strobel, A. (2015). What is Ethical Competence? The Role of Empathy, Personal Values, and the Five-Factor Model of Personality in Ethical DecisionMaking. Journal of Business Ethics, 137(3), pp.449-474. DOI: 10.1007/s10551-015-2569-5

Rest, J. R. (1986). Moral development: Advances in research and theory. New York, NY: Praeger.

Schyns, B. and Hansbrough, T. (2010). When leadership goes wrong. Charlotte, N.C.: Information Age Publishing.

Seldon, A. (2011). Trust: How we lost it and how to get it back. Biteback Publishing.

Siebert, S., Martin, G. and Bozic, B. (2016) Research into employee trust: epistemological foundations and paradigmatic boundaries, Human Resource Management Journal, Vol.26(3), pp.269-284 
Siltaoja, M., Lämsä, A. and Kujala, J. (2019). Theory to Practice- How Does Business Ethics Matter? 1st ed. University of Jyväskylä Press, pp.112-126.

Simpson, T. (2012). What Is Trust? Pacific Philosophical Quarterly, 93(4), pp.550-569. DOI: 10.1111/j.1468-0114.2012. 01438. $x$

Son Hing, L., Bobocel, D., Zanna, M. and McBride, M. (2007). Authoritarian dynamics and unethical decision making: High social dominance orientation leaders and high right-wing authoritarianism followers. Journal of Personality and Social Psychology, 92(1), pp.67-81.

Turner, J. (2018). Literature Review. Performance Improvement Quarterly, 31(2), pp.113-117. DOI: 10.1002/piq.21275

Woiceshyn, J. (2011) A Model for Ethical Decision Making in Business: Reasoning, Intuition, and Rational Moral Principles, Journal of Business Ethics, Vol.104(3), pp.311-323 